7. Gill JM, Mainous AG III, Diamond JJ, Lenhard MJ. Impact of provider continuity on quality of care for persons with diabetes mellitus. Ann Fam Med 2003;1:162-170.

8. De Maeseneer JM, De Prins L, Gosset C, Heyerick J. Provider continuity in family medicine: does it make a difference for total health care costs? Ann Fam Med 2003;1:144-148.

9. Franks P, Cameron C, Bertakis KD. On being new to an insurance plan: health care use associated with the first years in a health insurance plan. Ann Fam Med 2003;1:156-161.
10. Saultz JW. Defining and measuring interpersonal continuity of care. Ann Fam Med 2003:1:134-143.

11. Christakis DA. Continuity of care: process or outcome? Ann Fam Med 2003;1:131-133.

12. Sax L, Kautz KJ. Who first suggests the diagnosis of attentiondeficit/hyperactivity disorder? Ann Fam Med 2003;1:171-174.

13. Frey JJ 3rd. A journey to someplace better. Ann Fam Med 2003;1: 175-176.

\title{
EDITORIAL
}

\section{Continuity of Care: Process or Outcome?}

Dimitri A. Christakis, MD, MPH

Child Health Institute, University of Washington, Seattle, Wash

Ann Fam Med 2003:1:131-133. DOI: 10.1370/afm.86.

$\mathrm{P}$ erhaps nothing has been deemed more central to the salubrious patient-physician relationship than continuity of care: it is a core component of the Institute of Medicine's definition of primary care. ${ }^{1}$ Having a regular physician seems vital to the establishment of trust and is frequently lamented as belonging to a bygone era when solo practitioners predominated. ${ }^{2}$ Given such strong face validity, as well as the endorsement of professional societies, ${ }^{3}$ one might ask why the value of continuity need be proved. Why subject something as fundamental as consistent contact with a clinician to the scrutiny of the evidence-based medicine movement? Why not simply take it as an unassailably desirable thing?

For true skeptics, of course, nothing is to be exempted from rigorous study. ${ }^{4}$ Even for those who believe that continuity is inherently good, there are reasons to assess its potential effects, as authors in this issue of Annals of Family Medicine have done. Previous studies of continuity of care have led to conflicting conclusions as to its value. ${ }^{5-12}$ Furthermore, many

Conflict of interest: none reported

\section{CORRESPONDING AUTHOR}

Dimitri A. Christakis, MD, MPH

$6200 \mathrm{NE} 74^{\text {th }}$ St. Suite 210

Seattle WA 98115

dachris@u.washington.edu changes in care delivery arising in response to the increasingly competitive medical market place might potentially diminish continuity of care. The larger size of physician groups, the increasing use of physician extenders, and the shifting alliances of health plans with clinicians, all might hamper patients' or clinicians' attempts to establish and maintain consistent contact. ${ }^{2,13}$ Evaluating the effects of continuity of care might therefore be timely and necessary to countervail forces that could otherwise undermine it. So what more have we learned about continuity of care as a result of the studies in this issue?

Gill et a ${ }^{14}$ fail to find an association between continuity of care and some well-established process measures for high-quality care in diabetic patients. Although their findings appear to conflict with those of another similar study ${ }_{1}{ }^{15}$ there are some important distinctions. The general continuity of care achieved in their sample was quite good. A Continuity of Care index rating of .51 is considerably higher than what others have found in publically insured populations and even higher than was achieved in a randomized trial of continuity of care. ${ }^{5,6}$ Second, the overall quality of care, at least with respect to regular measurement of glycosylated hemoglobin levels, was quite good-an annual screening rate of $81 \%$ might rightly be envied by many medical directors. The high levels of general continuity of care and overall quality of care might combine to create a ceiling effect, which means that 
the null findings might not apply to other populations with lower continuity and poorer glycemic control. Their article, however, does raise a persistent and important point: the question might not be, "Does continuity of care make a difference at a population level?" but rather, "Are there specific subpopulations for which continuity of care is especially valuable?" For most healthy, wealthy, young individuals, contact with a physician is unlikely to have a measurable impact on their already good health.

Nutting et $\mathrm{al}^{16}$ address the important point that continuity of care might be differentially important for different types of patients during different types of visits. They show that, indeed, more vulnerable populations by dint of age or chronic disease or socioeconomic status value continuity of care more. Is valuing continuity of care an outcome in and of itself that validates its importance? Although patient satisfaction is considered by many as an outcome rather than a process measure, patients can be satisfied with care that is of poor quality and not evidence based. ${ }^{17}$ In fact, liking or trusting their physician might well be precisely what makes patients feel their care is of high quality even when it is not. Ironically, consistent contact with a suboptimal physician might be far from desirable.

The critical reality is that what is likely valued by a patient not simply continuity of care but rather a relationship with a clinician. As Sault $z^{18}$ points out in his synthesis of a large and complex literature, what we are striving for is interpersonal continuity that leads to trust and mutual respect. Any index-based measure, such as the many that have been used to quantify continuity of care, can serve only as a proxy for interpersonal continuity. Continuity of care is ultimately necessary but not sufficient to create an opportunity for clinicians and patients to get to know each other well. As De Maeseneer and colleagues ${ }^{19}$ report, continuity is associated with lower health care costs, adding a monetary incentive for health plans to strive to achieve it.

In health services research parlance, the articles in this issue collectively suggest that we have yet to resolve whether continuity of care is a process or an outcome. Is its value only measurable insofar as it is a means to an identifiable end-improved glycosylated hemoglobin levels, decreased unnecessary hospitalizations - or can we state that it is worth achieving in its own right? This distinction is critical. If continuity of care is deemed an outcome, then it can become a benchmark of the quality of care (much as glycosylated hemoglobin is currently). It will cease to become an independent variable and will become a dependent variable in subsequent research. Means of improving and maintaining it will be developed, implemented, and evaluated.

I think that the preponderance of evidence from articles presented in this issue, as well as previous studies, suggests that it is time to declare continuity of care an outcome and to spur subsequent research in how to better achieve it. ${ }^{6,8-10,12,20}$ Certainly the findings of the studies in this issue of Annals, that potentially high-risk patients value continuity and that continuity of care saves health care dollars, begin to make the case for continuity as an outcome worthy of efforts by patients, clinicians, and health care systems to achieve it.

Many important empirical questions remain, however. Should continuity of care be foisted on those for whom it does not matter or who do not want it? Should health plans adopt an arranged marriage approach between patients and clinicians: "You will learn to love each other?" Is it merely that those with no interest in having a regular physician do not know what they are missing, either because they have never had one or because they have not been sick enough to feel they needed the counsel of someone with whom they had a relationship? Does providing summaries of the continuity of care that practices (or plans) achieve affect patient selection of insurers or clinicians, as Consumer Assessment of Health Plan data currently

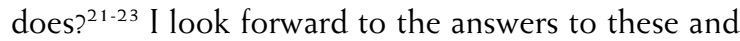
other related questions, perhaps in the pages of a subsequent issue of Annals of Family Medicine.

To read commentaries or to post a response to this article, see the online version at http://annfammed/cgi/content/full/1/3/131.

\section{References}

1. Institute of Medicine. Defining primary care: an interim report. Washington, DC; 1994.

2. Bodenheimer T, Lo B, Casalino L. Primary care physicians should be coordinators, not gatekeepers. JAMA 1999;281:2045-2049.

3. American Academy of Pediatrics Ad Hoc Task Force on Definition of the Medical Home. The medical home. Pediatrics 1992;90:774.

4. Sackett DL, Haynes RB, Guyatt GH, Tugwell P. Clinical epidemiology: a basic science for clinical medicine. 2nd ed. Boston, Mass: Little, Brown; 1991:307.

5. Christakis DA, Mell L, Koepsell TD, Zimmerman FJ, Connell FA. Association of lower continuity of care with greater risk of emergency department use and hospitalization in children. Pediatrics 2001;107:524-529.

6. Wasson JH, Sauvigne AE, Mogielnicki RP, et al. Continuity of outpatient medical care in elderly men. JAMA 1984;252:2413-2417.

7. Roos LL, Roos NP, Gilbert P, Nicol JP. Continuity of care: does it contribute to quality of care? Med Care 1980;18:174-184

8. Mainous AG III, Gill JM. The importance of continuity of care in the likelihood of future hospitalization: is site of care equivalent to a primary clinician? Am J Public Health 1998;88:1539-1541.

9. Gill JM, Mainous AG III. The role of provider continuity in preventing hospitalizations. Arch Fam Med 1998;7:352-357. 
10. Gill JM, Mainous AG III, Nsereko M. The effect of continuity of care on emergency department use. Arch Fam Med 2000:9:333-338.

11. Gordis L, Markowitz M. Evaluation of the effectiveness of comprehensive and continuous pediatric care. Pediatrics 1971;48:766-776.

12. Alpert JJ, Robertson LS, Kosa J, Heagarty MC, Haggerty RJ. Delivery of health care for children: report of an experiment. Pediatrics 1976;57:917-930

13. Flocke SA, Stange KC, Zyzanski SJ. The impact of insurance type and forced discontinuity on the delivery of primary care. J Fam Pract 1997:45:1291-35.

14. Gill JM, Mainous AG 3rd, Diamond JJ, Lenhard MJ. Impact of provider continuity on quality of care for persons with diabetes mellitus. Ann Fam Med 2003;1:162-170.

15. Christakis DA, Feudtner C, Pihoker C, Connel FA. Continuity and quality of care for Medicaid children. Ambulatory Pediatr 2001;1:99103.

16. Nutting PA, Goodwin MA, Flocke SA, Zyzanski SJ, Stange KC. Continuity of primary care: to whom does it matter and when? Ann Fam Med 2003;1:149-155.

17. Cleary PD, McNeil BJ. Patient satisfaction as an indicator of quality care. Inquiry 1988;25:25-36.

18. Saultz JW. Defining and measuring interpersonal continuity of care Ann Fam Med 2003;3:[PAGES HERE].

19. De Maeseneer JM, De Prins L, Gosset C, Heyerick J. Provider continuity in family medicine: does it make a difference for total health care costs? Ann Fam Med 2003;3:144-148

20. Alpert JJ, Kosa J, Haggerty RJ, Robertson LS, Heagarty MC. Attitudes and satisfactions of low-income families receiving comprehensive pediatric care. Am J Public Health Nations Health 1970;60:499506.

21. Goldstein E, Fyock J. Reporting of CAHPS quality information to Medicare beneficiaries. Health Serv Res 2001;36:477-488.

22. Guadagnoli E, Epstein AM, Zaslavsky A, et al. Providing consumers with information about the quality of health plans: the Consumer Assessment of Health Plans demonstration in Washington State. Jt Comm J Qual Improv 2000;26:410-420.

23. Homer CJ, Fowler FJ, Gallagher PM, et al. The Consumer Assessment of Health Plan Study (CAHPS) survey of children's health care. Jt Comm J Qual Improv 1999;25:369-377.

\section{ANNALS OF FAMILY MEDICINE} CHANGE-OF-ADDRESS FORM

Please complete this form and mail to the following address or fax to Annals Circulation at 913-906-6080

Annals of Family Medicine

Circulation Department

11400 Tomahawk Creek Pkwy

Leawood, KS 66211-2672

Check if member of sponsoring organization:
AAFP
ABFP
STFM
ADFM
AFPRD
NAPCRG

ID number from label

on your journal cover

OLD INFORMATION (Please print.)

Name

Company (if applicable)

Address (Street plus Apt or Ste)

City State

\begin{tabular}{ll}
\hline Country & Postal Code (9-digit ZIP for US)
\end{tabular}

Telephone

Fax

E-Mail

NEW INFORMATION (Please print.)

Name

Company (if applicable)

Address (Street plus Apt or Ste)

\begin{tabular}{ll}
\hline City & State \\
\hline Country & Postal Code (9-digit ZIP for US) \\
\hline Telephone & Fax \\
\hline E-Mail & \\
\hline
\end{tabular}

